\title{
Learning English through Serious Games - Reflections on Teacher and Learner Performance
}

\author{
Bente Meyer \\ Associate Professor, Department of Curriculum Research, Danish School of Education, \\ University of Aarhus, \\ $(+45) \quad 8888 \quad 9509$ \\ bmadpu. dk
}

In this paper I am exploring the challenges of designing game-based material for language learning as a specific field of competence. The empirical context of the paper is a project on Serious Games on a Global Market Place (2007-10) in which academics work with companies to explore, build and implement game prototypes. One aspect of this research consists in analysing and developing a design for learning English through serious games (www.mingoville.com) as well as exploring how this design is used and implemented in classroom teaching and learning. We studied the use of the platform in two classes with children aged 10-11.

As the study described aimed to understand the performance and role of the teacher and learners in the classroom during game-based teaching and learning, we had suggested to teachers that they use the platform in the ways that they found most relevant for their teaching. This approach allowed us to see how teachers managed, negotiated, and conceptualised gaming in the classroom as an aspect of teaching English as a foreign language.

The activities of the children in the classrooms studied showed that children were generally attracted to the most game- and play-like activities in the platform and that whenever possible, they would often choose these activities instead of activities that were more recognizable as traditional learning activities, for instance spelling exercises. In the $5^{\text {th }}$ form class the exploratory approach to the platform chosen by the teacher inspired children to identify the platform with gaming activities and to explore challenges and playful activities rather than persevering for the sake of learning content. In the $4^{\text {th }}$ form class pupils would also chose gaming activities if allowed, however, pupils were generally directed by teacher guidance and intervention to complete tasks and persevere in order to learn. These differences in platform use and performance suggest not only that pupils prefer to be players rather than learners if these roles are not integrated in serious game design, but also that the ontological perspectives on games often discussed in game theory are not sufficient to understand how games work in education [10]. Rather than asking "what is a game?" we should therefore explore the performative and social aspects of gaming in and out of classrooms. Exploratory and directed approaches to using games in the classroom are in this sense not outside perspectives added to the core of the game itself, but integrated aspects of the game understood as an actor in teaching and learning English in a formal learning context in Denmark. 